\title{
Analysis of Load Carrying Capacity of Strip Footing Resting on Geogrid Reinforced Fly-Ash Over an Earthen Slope Using Plaxis2D
}

\author{
D.O.I - 10.51201/Jusst12601 \\ http://doi.org/10.51201/Jusst12601 \\ Tahir Mohammad Bhat ${ }^{1}$, Dr. Prashant Garg ${ }^{2}$, Gagandeep Kaur Grewal ${ }^{3}$ \\ ${ }^{1} P G$ Student, Department of Civil Engineering, GNDEC, Ludhiana, India. \\ ${ }^{2}$ Assistant Professor, Department of Civil Engineering, GNDEC, Ludhiana, India. \\ $3^{3}$ Assistant Professor, Department of Civil Engineering, GNDEC, Ludhiana, India.
}

\begin{abstract}
The current study deals with the use of material waste such as fly ash as a fill material or replaced layer placed over an earthen slope and strip footing is placed over the slope in order to explore the benefits of using geogrid sheets to strengthen the fly ash layer and to investigate its effects on the load carrying capacity. Using Program PLAXIS-2D v8.2, the fly-ash sheet is positioned over an earthen slope with slope inclination of $3 \mathrm{H}: 2 \mathrm{~V}$, and multiple type of models were investigated, to study the integration impact of geogrid-reinforcement layers on load carrying ability. For optimal improvement in load carrying ability, models have been tested to evaluate the best location, length and configuration of geogrid layers and top fly-ash layer depth. In order to evaluate the effect of one parameter in each sequence the other factors were kept constant. The sequence of findings was illustrated using PLAXIS-2D on the strip base in both strengthened and unreinforced cases. Test findings demonstrate that inclusion of geogrid significantly enhances efficiency of slope and footing.
\end{abstract}

Keywords: Fly-ash, Geogrid-Reinforcement, Plaxis-2D, Earthen Slope.

\section{Introduction}

In several situations, foundations in different civil engineering applications are often built close to the slopes, which mostly include buildings, bridge abutments, highway pavements embankments and transmission towers. However, stability and durability of such structures adjacent to slope edges is a challenging problem, as both durability and load carrying ability of such footings and embankments are taken into consideration. Therefore, the concept of earth slope strengthening has been one of the important fields for scientific over several years. Typical examples include the alteration of the slope surface, chemical grouting, use of geosynthetic sheets as reinforcing material etc. The present research deals with the usage of waste product such as fly-ash as a structural fill or replaced layer in case of foundation and highway embankments over an earthen or clayey slope. In order to boost the load bearing strength of fly-ash, geogrid is used as a reinforcing agent in fly-ash layer slope Using PLAXIS-2D, the prototype soil model is examined for the condition of plane-strain, and the analysis purpose Mohr-Coulomb method is used. For the good precision of the results, mesh is generated with the use of 15-noded triangular elements of medium coarseness. The sheet of fly-ash was placed on an earthen soil with inclination of $3 \mathrm{H}: 2 \mathrm{~V}$. Various prototype models were analyzed to investigate the influence of the geogrid reinforcing sheets on load carrying ability.

In order to obtain the optimum value of loading capacity in each prototype model tests, during the influence of one parameter, the other parameters were kept constant. The different conditions involved in investigation the load carrying capacity include the thickness of top fly-ash sheet, horizontal gap between the footing and the slope edge, number and length of geogrid layers and vertical spacing of reinforcements. Although several research studies have also identified that the efficient use of geogrid as a reinforcing agent in various soft soils such as poor subgrade etc. The main objective of the present research is to examine many important issues, which includes the influence of geogrid as a reinforcing agent on the results and to understand the method and mechanism of reinforcement of reinforcement, and also to suggest the optimum number of reinforcements, edge distance and vertical spacing between the reinforcement sheets. 


\section{Material Properties}

In this research study, the soil model was modeled using the method of Mohr-Coulomb. Parameters that are required to specify the soil slope model in each analysis for both fly-ash and earthen soil are obtained from previous literature El Sawwaf (2007) [1] and A. K. Choudhary et. al. (2009) [2]. These are cohesion(c), internal friction angle $(\phi)$, modulus of elasticity (E) and Poisson's ratio $(\mu)$. Moreover, dry unit weight $(\gamma$-dry) of the soil model slope was used and reduction factor must be defined (R-inter). The different properties of materials used in prototype soil slope model obtained from the previous literature are listed below:

\subsection{Earthen Soil (Clayey Soil)}

The properties of earthen soil (clay soil) used during the prototype model tests were obtained from the available literature data from El Sawwaf (2007) [1]. The properties of this soil are given in table 2.1.

Table 2.1 Soft Clay Properties (earthen soil)

\begin{tabular}{|c|c|}
\hline Liquid limit & $39 \%$ \\
\hline Plastic limit & $21 \%$ \\
\hline Shrinkage limit & $13 \%$ \\
\hline Optimum moisture content-(OMC) & $17 \%$ \\
\hline Consistency Index & 0.44 \\
\hline Plasticity Index & $18 \%$ \\
\hline Dry unit of soil & $15.84 \mathrm{KN} / \mathrm{m}^{3}$ \\
\hline Cohesion & $25 \mathrm{KN} / \mathrm{m}^{2}$ \\
\hline Internal friction angle & $5^{\circ}$ \\
\hline
\end{tabular}

\subsection{Fly-Ash}

Fly-ash is the finely divided powder in power generation powder plants that is a by-product of burning pulverized coal and is carried by exhaust gases from combustion chamber. In current research, using finite element analysis, the properties of fly ash are obtained from the available data from A. K. Choudhary et. al. (2009)[2] and during the tests fly-ash used in prototype model was produced from TISCO (Tata Iron and Steel Company Limited), Jamshedpur, India. Fly ash consists of 68 percent silt and 28 percent sand, as per the particle size distribution. $9.34 \mathrm{KN} / \mathrm{m}^{3}$ and 48 per cent respectively were the full dry density and optimal moisture content (OMC) of fly ash. The properties of fly-ash are given in table 2.2 .

Table 2.2 Fly-ash Properties

\begin{tabular}{|c|c|}
\hline Dry unit weight & $13.82 \mathrm{KN} / \mathrm{m}^{3}$ \\
\hline Cohesion Value & $20 \mathrm{KN} / \mathrm{m}^{2}$ \\
\hline Poisson's Ratio & 0.38 \\
\hline Internal Friction Angle & $14^{\circ}$ \\
\hline
\end{tabular}

\subsection{Geogrid-Reinforcement}

Geogrid is a geosynthetic substance made of polymeric material that is used to stabilize soils, rocks and similar materials. for the model experiments in current research, the geogrid used is Tenax TT Samp with peak tensile strength of $45 \mathrm{KN} / \mathrm{m}^{3}$ as a reinforcing material. The geogrid used is fabricated by extruding HDPE (high density poly-ethylene) grids of mono-directional drawings. The physical and technical properties of geogrid reinforcing material used are given in table 2.3. 
Table 2.3 Geogrid-Reinforcement Properties

\begin{tabular}{|c|c|}
\hline Structure & Geogrid with Mono-Orientation \\
\hline Size of Aperture- $(\mathrm{mm} \times \mathrm{mm})$ & $(13 / 20) \times 220$ \\
\hline Shape of Aperture & Oval-Apertures \\
\hline Form of Polymer & HDPE \\
\hline Weight $\left(\mathrm{g} / \mathrm{m}^{2}\right)$ & 300 \\
\hline At 2 percent strain $(\mathrm{KN} / \mathrm{m})$ Tensile power & 11 \\
\hline Peak tensile power $(\mathrm{KN} / \mathrm{m})$ & 45 \\
\hline Elongation of Yield point (percent) & 11.5 \\
\hline Long term design strength $(\mathrm{N} / \mathrm{m})$ & 21.2 \\
\hline
\end{tabular}

\section{Prototype Study and Methodology}

Using PLAXIS-2D version 8.2 with the available data from previous article, the load carrying capacity of both reinforced and non-reinforced fly ash over an earthen soil slope is examined. The measurements are evaluated in the study and the variability of parameters is tested, affecting the efficiency of load carrying capacity.

\subsection{Finite Element Method}

In present work, in order to check the outcomes, various tests are conducted using two-dimensional finite element analysis (FEA) on a prototype footing slope model using PLAXIS program, in order to understand the load carrying capacity behavior of strip footing resting on a geogrid-reinforced fly ash slope over an earthen slope. As from El Sawwaf (2007)[1], prototype soil model was assumed to resting on a yielding base and to extend laterally to a distance of 1.5 times the slope height $(\mathrm{H})$. also, geometry of test footing prototype slope was assumed to be 10 times the laboratory model as in El Sawwaf (2007) [1]. Fly ash placed over the earthen slope is having the same inclination of $3(\mathrm{H}): 2(\mathrm{~V})$, and the material geogrid is used as reinforcing material in test slope. The software is allowed to perform plane- strain, Mohr-Coulomb analysis using 15-noded triangular elements and medium coarseness mesh is generated. The prototype slope geometry is shown in fig. 3.1

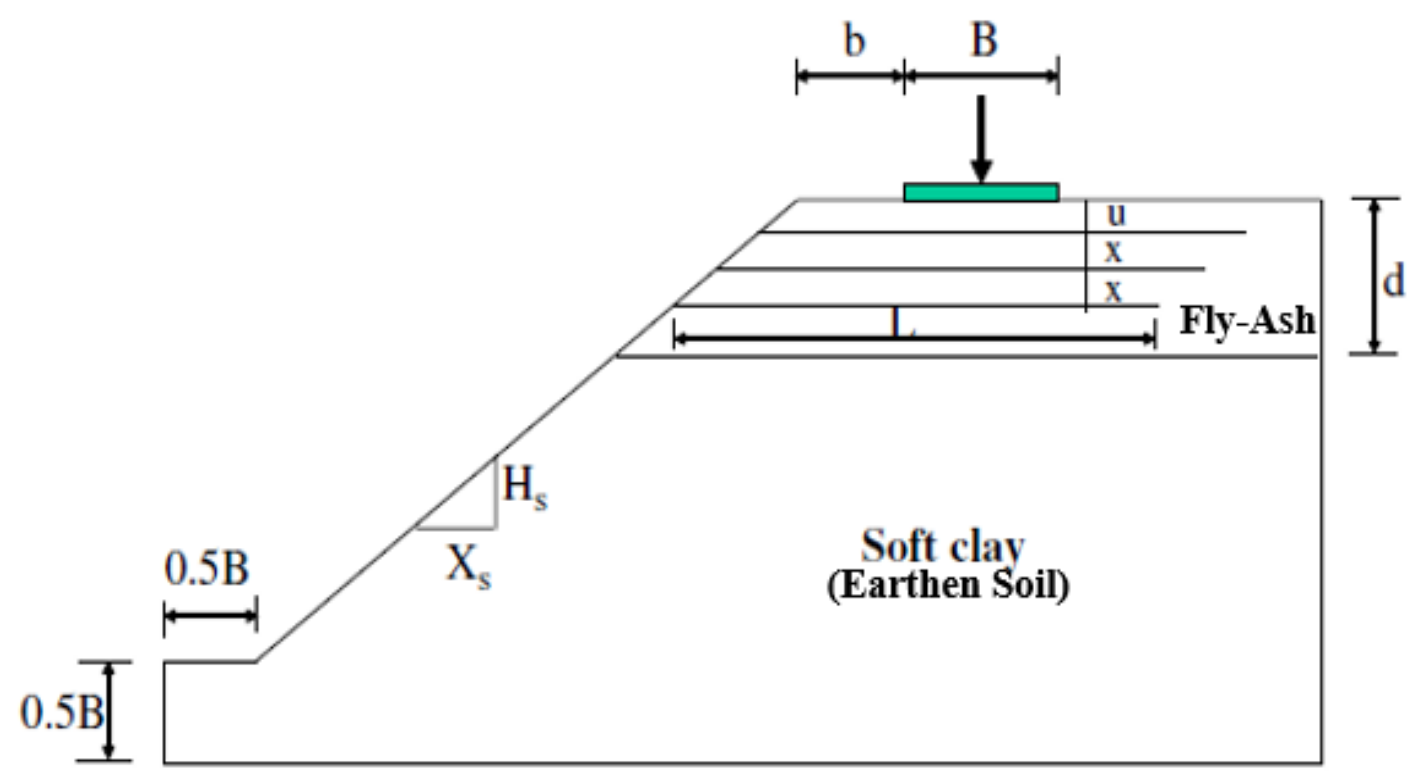

Fig. 3.1 Slope Model Used in PLAXIS-2D 
Table 3.1 Criteria Used in Finite Element Method (PLAXIS-2D)

\begin{tabular}{|c|c|c|c|}
\hline Parameter & $\begin{array}{c}\text { Earthen } \\
\text { Soil }\end{array}$ & Fly-Ash & Footing/Geogrid \\
\hline Cohesion Value $\left(\mathrm{C}-\mathrm{KN} / \mathrm{m}^{2}\right)$ & 25 & 20 & ---- \\
\hline Angle of friction $(\phi)$ & 5 & 14 & ---- \\
\hline Dry Unit Weight $\left(\gamma-\mathrm{KN} / \mathrm{m}^{3}\right)$ & 15.84 & 13.82 & ----- \\
\hline Poisson's ratio $(\mu)$ & 0.33 & 0.38 & ---- \\
\hline Primary loading stiffness $\left(\mathrm{E}-\mathrm{KN} / \mathrm{m}^{2}\right)$ & 1000 & 8000 & ----- \\
\hline Interface reduction factor $(\mathrm{R}-\mathrm{inter})$ & 0.5 & 0.55 & ----- \\
\hline Angle of Dilatancy $(\psi)$ & 0.0 & 0.0 & ----- \\
\hline Footing EA value-(KN/m) & ----- & ----- & 5000000 \\
\hline Footing EI value- $(\mathrm{KN}$ m²/m) & ---- & ---- & 8500 \\
\hline Geogrid EA value- $(\mathrm{KN} / \mathrm{m})$ & ----- & ---- & 2000 \\
\hline Footing width $(\mathrm{B})-\mathrm{m}$ & ----- & ---- & 0.75 \\
\hline Footing thickness $(\mathrm{t})-\mathrm{m}$ & ---- & - & 0.2 \\
\hline
\end{tabular}

Table 3.2 Parameters used in Evaluation Software Model

\begin{tabular}{|c|c|c|}
\hline $\begin{array}{c}\text { Test } \\
\text { Series } \\
\end{array}$ & Constant Parameters & Variable Parameters \\
\hline 1 & Non-reinforced slope Testing, $\mathrm{b} / \mathrm{B}=0$ & $\mathrm{~d} / \mathrm{B}=0.5,1,1.5,2,3$ \\
\hline 2 & $\mathrm{R} / \mathrm{F}$ Slope Testing, $\mathrm{b} / \mathrm{B}=0, \mathrm{~d} / \mathrm{B}=1.5, \mathrm{~N}=1, \mathrm{~L} / \mathrm{B}=5$ & $\begin{array}{c}\mathrm{u} / \mathrm{B}=0.25,0.5,0.75,1, \\
1.25\end{array}$ \\
\hline 3 & $\mathrm{~b} / \mathrm{B}=0, \mathrm{~d} / \mathrm{B}=1.5, \mathrm{~N}=2, \mathrm{u} / \mathrm{B}=0.25, \mathrm{~L} / \mathrm{B}=5$ & $\mathrm{x} / \mathrm{B}=0.25,0.5,0.75,1$ \\
\hline 4 & $\mathrm{~b} / \mathrm{B}=0, \mathrm{~d} / \mathrm{B}=1.5, \mathrm{~N}=3, \mathrm{u} / \mathrm{B}=0.25, \mathrm{x} / \mathrm{B} 0.4$ & $\begin{array}{c}\mathrm{b} / \mathrm{B}=0, \mathrm{~d} / \mathrm{B}=1.5, \mathrm{~N}=3, \\
\mathrm{u} / \mathrm{B}=0.25, \mathrm{x} / \mathrm{B} 0.4\end{array}$ \\
\hline 5 & $\mathrm{~b} / \mathrm{B} 0, \mathrm{~d} / \mathrm{B}=1.5, \mathrm{u} / \mathrm{B}=0.25, \mathrm{x} / \mathrm{B} 0.4, \mathrm{~L} / \mathrm{B}=6$ & $\mathrm{~N}=1,2,3,4,5$ \\
\hline 6 & Non-reinforced Slope Testing, $\mathrm{d} / \mathrm{B}=1.5$ & $\mathrm{~b} / \mathrm{B}=0,1,2,3,4$ \\
\hline 7 & $\begin{array}{c}\text { RF Slope Testing, } \mathrm{d} / \mathrm{B}=1.5, \mathrm{~N}=3, \mathrm{u} / \mathrm{B}=0.25, \mathrm{x} / \mathrm{B}=0.4, \\
\mathrm{~L} / \mathrm{B}=5\end{array}$ & $\mathrm{~b} / \mathrm{B}=0,1,2,3,4$ \\
\hline
\end{tabular}




\section{Results and Discussion}

In the present work, using PLAXIS-2D program, total 34 prototype tests were carried out and footing assisted on fly ash sheet over soft clay slope. In both reinforced and un-reinforced situations, the impact of geogrid length, footing edge distance, thickness of fly-ash sheet and number of geogrid layers on the load carrying capacity was examined. The soil model is intended for the state of the plane-strain, and the thesis uses the model of Mohr-Coulomb. The mesh generation is achieved with the use of fifteen (15) node triangular elements of mild coarseness for good precision of outcomes.

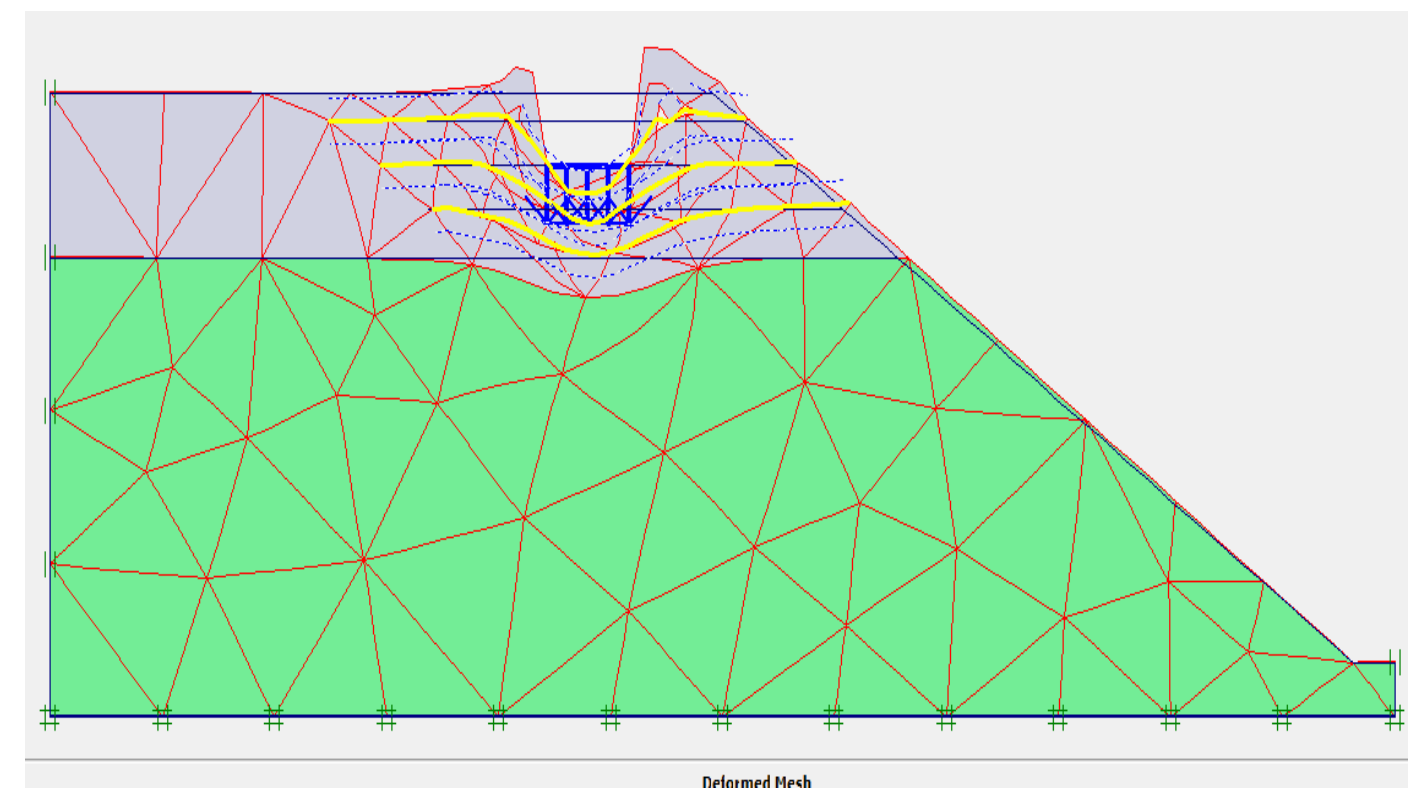

Fig. 4.1 Mesh Deformation in the Strengthened slope model.

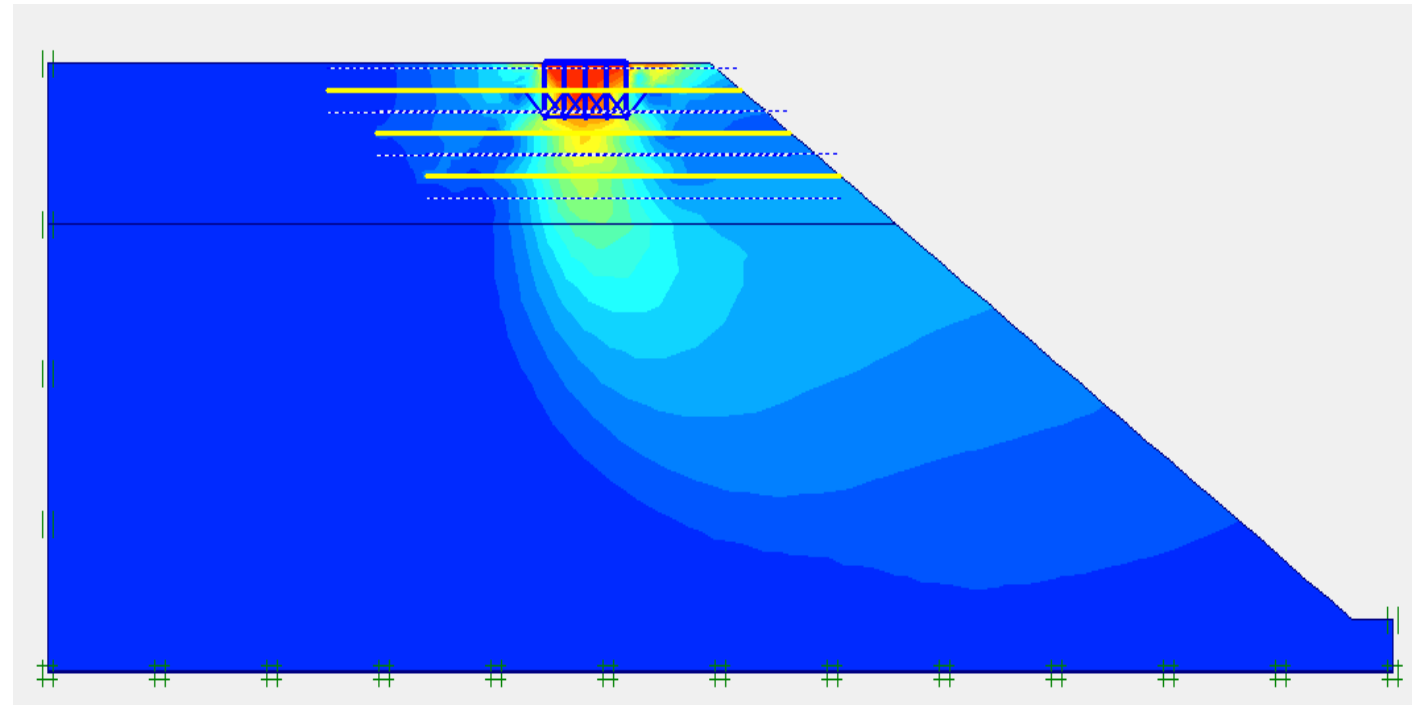

Fig. 4.2 Total displacement shading for the reinforced slope model 


\subsection{Effect of thickness of the top fly-ash sheet on load carrying capability}

Prototype model was examined using PLAXIS-2D, the footing is positioned with zero edge distance $(b=0)$ and the depth of top fly-ash sheet that was placed above the slope of clayey soil (earthen slope) was differed. The load was applied to the base and the load capacity of load was determined by varying the depth of the top fly ash layer and the results were than plotted in fig.4.3. Graph clearly illustrates that the loading potential is greatly improved by increasing the depth of the replaced fly-ash sheet. However, it's evident that at depth more than $1.5 \mathrm{~B}$, load carrying capacity of footing does not gets much affected. This means that beyond 1.5B-2B (where $\mathrm{B}=$ width of footing) varying depth or thickness of fly-ash layer does not affect load carrying capacity too much.

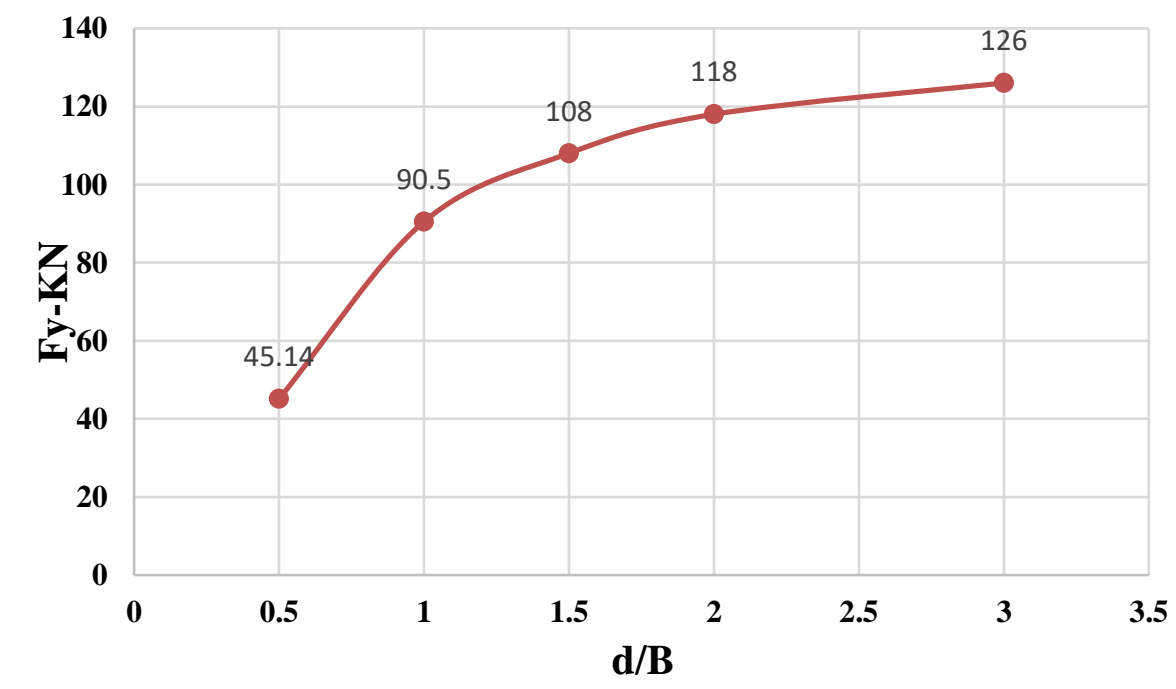

Fig. 4.3 Load carrying capacity combinations with different depths of fly-ash.

\subsection{Impact of top geogrid layer's depth on load carrying capacity}

In this case, the influence of the top geogrid-reinforcement layer on the load carrying ability of footing slope was examined. Five tests were carried out using only one layer of reinforcement at different depths in fly ash layer. It was observed that load bearing capability initially increases before a limit value is reached, and after which curve begins to descend with a further increase in geogrid layer depth from base. A depth ratio of $\mathrm{u} / \mathrm{B}=0.58$ was observed from the curve at which the reinforcement effect is maximum as shown in fig. 4.4 .

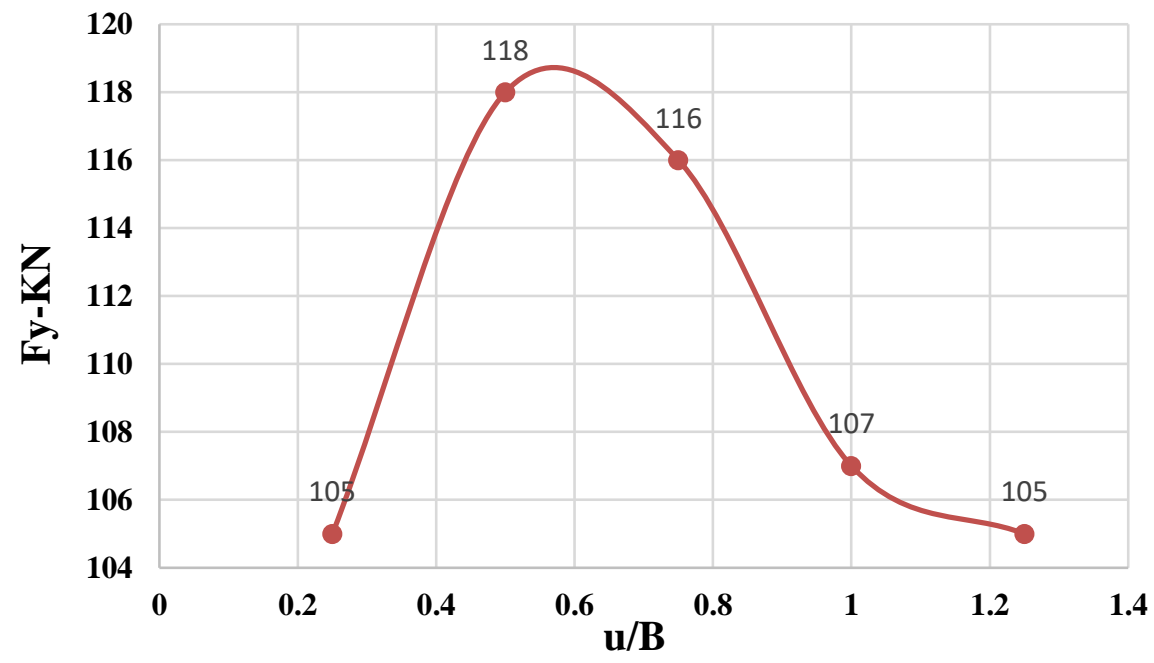

Fig.4.4 Changes in load capacity with geogrid layer depth $\mathbf{u} / \mathbf{B}$. 


\subsection{Impact of number of Reinforcement layers on load carrying ability}

Plaxis-2D experiments were performed to examine the impact of varying the number of strengthening geogrid layers on the performance of the base slope. The fly ash sheet thickness of $1.5 \mathrm{~B}$ along with geogrid length of $\mathrm{L}=6 \mathrm{~B}$, geogrid spacing and position were kept constant, although the number of geogrid layers are varied. It was noted that significant enhancement occurs when geogrid numbers are 3 to 4 , and results are not greatly influenced by any rise in count of geogrid sheets as shown in fig. 4.5. Such enhancement is due to interlocking between geogrid sheets and fly -ash particles. The mobilized tension produced by the earth pressure in the strengthening layers enables the geogrid-reinforcement to withstand the entire load or pressure formed in the soil mass and transfers it to the adjacent stable soil layers, leading to a larger and deeper failure zone.

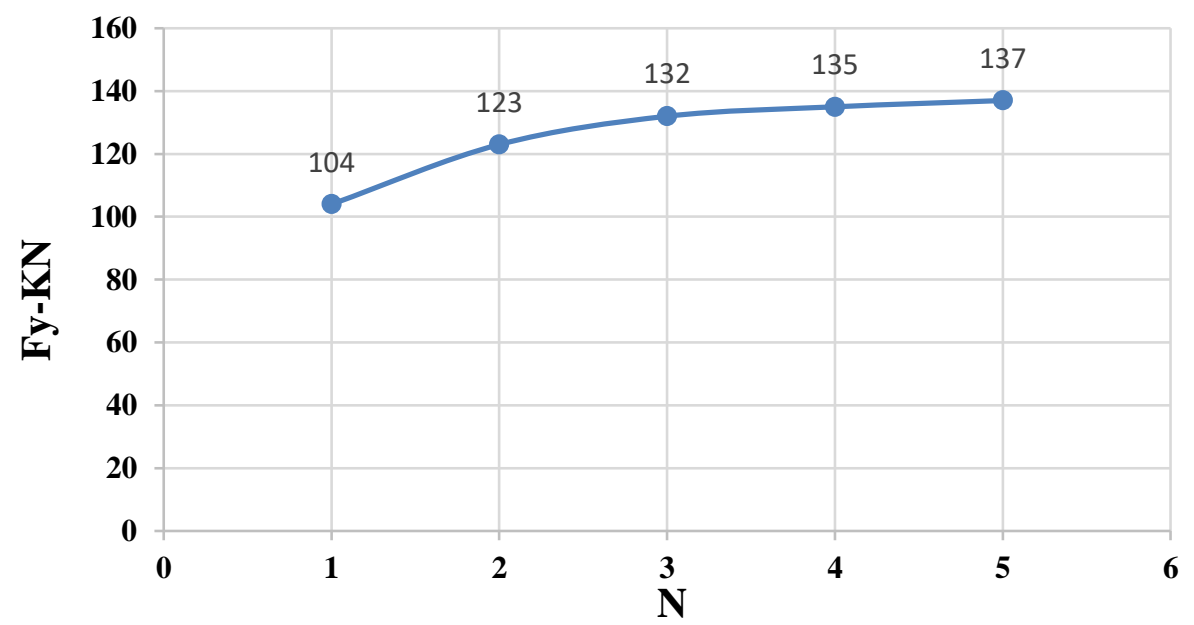

Fig. 4.5 Variations of failure load (Fy) with geogrid layer number $(\mathrm{N})$.

\subsection{Effect of geogrid-length on load carrying capability}

The optimum length of reinforcement layers in the fly ash sheet are provided in order to have adequate anchorage length for effective reinforcement. Five tests were carried out on different lengths of reinforcement layers and results are plotted in fig. 4.6. The results illustrate that loading capacity increases with increasing of reinforcement layers. However, this rise in load capacity is up to the value of $5 \mathrm{~B}$ to $5.5 \mathrm{~B}$ (where $\mathrm{B}$ is footing width), beyond which further increase in length does not make essential contribution to loading capacity. Yoo[3] also suggested that $\mathrm{L} / \mathrm{B}=5$ to 5.5 is an acceptable length of geogrid-reinforcement to maximize the efficacy of reinforcement by optimum pullout potential for reinforcement.

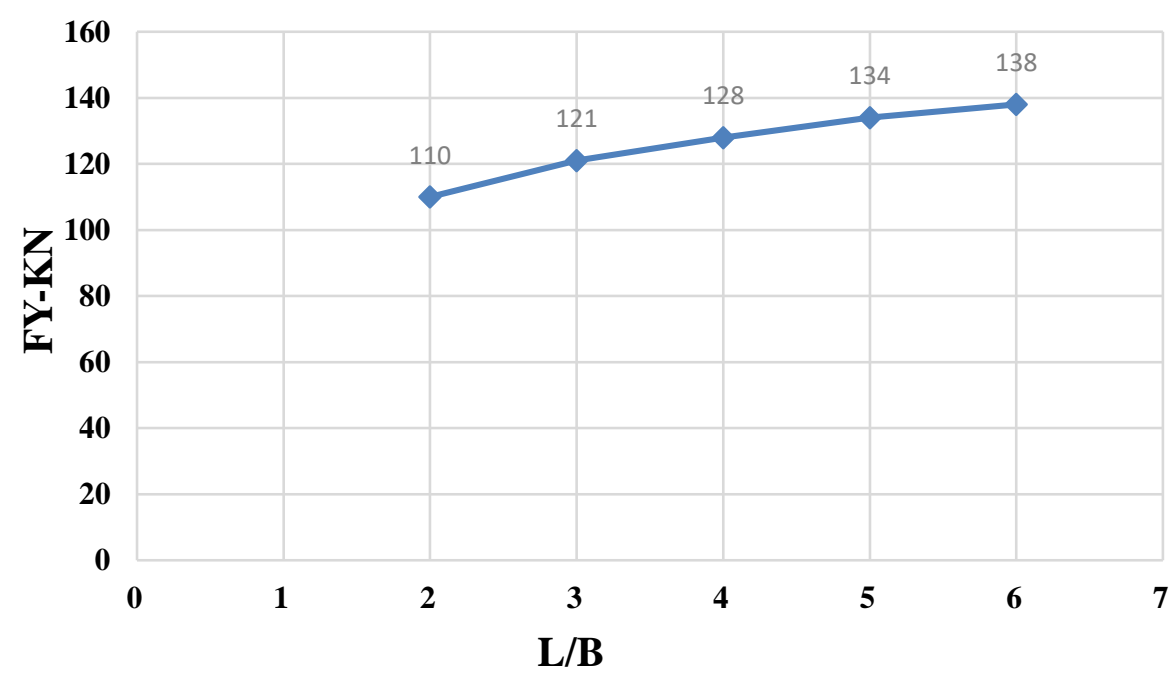

Fig. 4.6 Load Variance with geogrid layer Length. 


\subsection{Impact of footing edge distance relative to crest of slope}

Tests were performed in both reinforced and non-reinforced slopes in order study the influence of edge distance (d) of footing relative to slope crest on load carrying capacity. In case of reinforced slope three- geogrid layers were used and obtained results in both cases were plotted on graph shown in fig. 4.7. Results illustrate that ultimate load carrying capacity increases in both cases as edge distance is increased. However, this improvement is sufficient up to crest distance of 3B to 4B, after which slope effect seems too negligible. This increase in the load carrying ability of the base with respect to slope edge distance is due to the friction of soil and the impact of reinforcement against the lateral movement of the soil or the fault wedge. As when footing is positioned away from the edge of the slope, soil resistance to lateral displacement increases and geogrid usage often decreases soil displacement and leads to broader and deeper failure region, ultimately enhancing the footing loading ability.

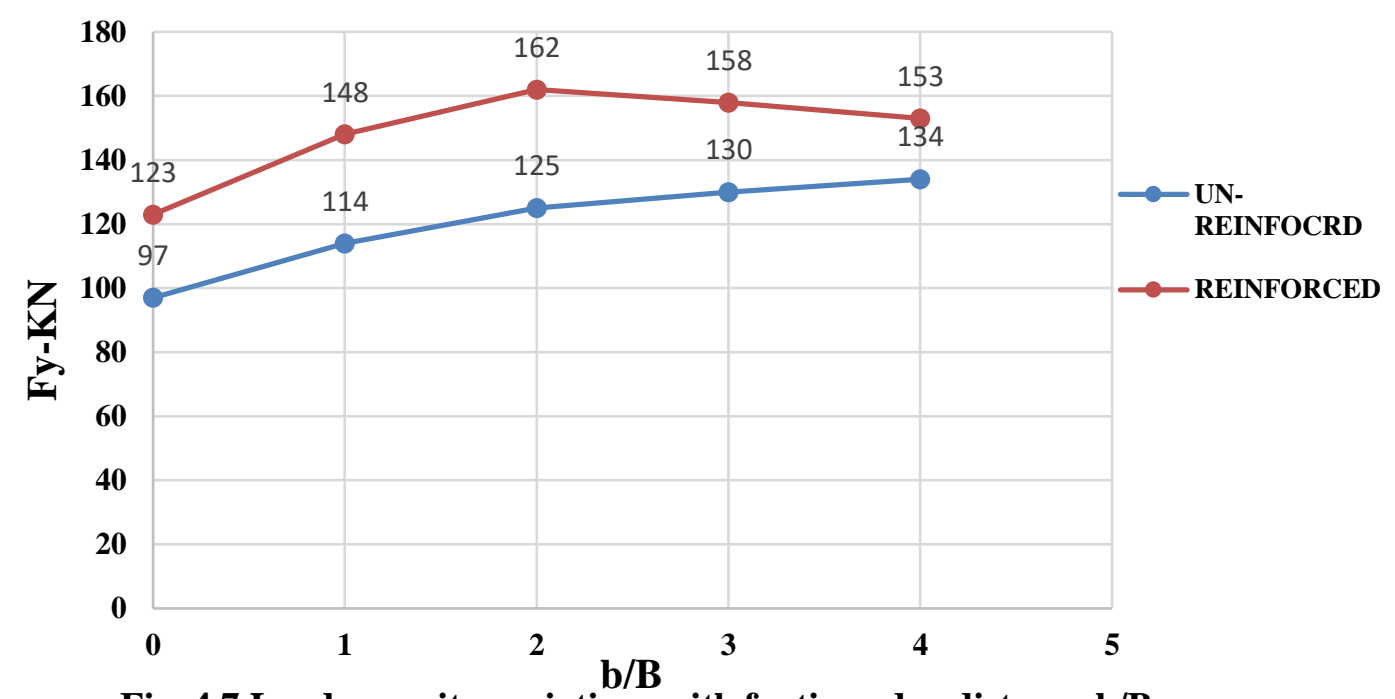

Fig. 4.7 Load capacity variations with footing edge distance $b / B$.

\subsection{Impact of vertical spacing of Geogrid-reinforcement}

In this case, the footing was maintained at the slope edge, only vertical spacing of reinforcement layers are differed, rest all other parameters are kept constant. Two layers of reinforcement were used with varied spacing values of $\mathrm{x}=0.25 \mathrm{~B}, 0.5 \mathrm{~B}, 0.75 \mathrm{~B}$ and $1 \mathrm{~B}$. Results show that loading capacity initially increases up to it reaches to optimum value, after which it starts decreasing. From fig. 4.8, it was observed that optimum value of spacing in this case is approximately $\mathrm{x} / \mathrm{B}=0.5$, after which it begins to decrease. Yoo[3] recorded similar graph for the entirely sandy slope, for which the critical value was $\mathrm{x} / \mathrm{B}=0.7$.

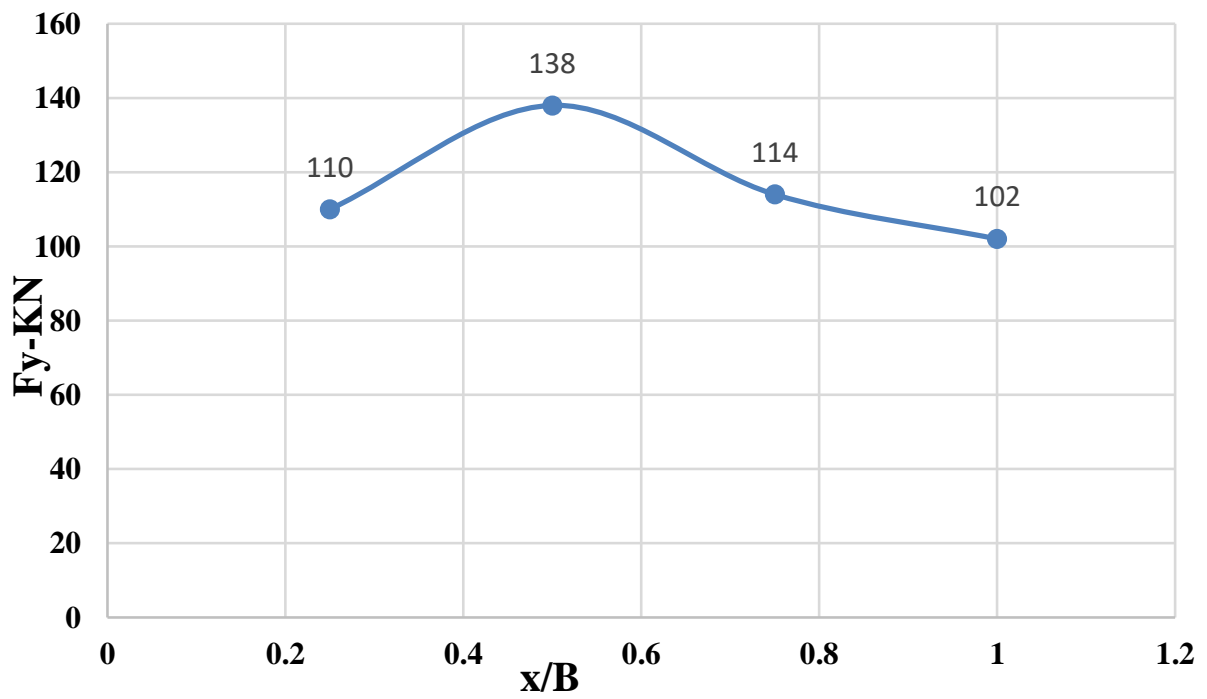

Fig. 4.10 Load capability variations with vertical gap of reinforcing-geogrid. 


\section{Conclusions}

Based on the outcomes of current study, relevant conclusions may be drawn, as mentioned below.

1 Strength and loading capacity of Soft clay soil (earthen soil) present on slopes or under foundations can be significantly enhanced when partially replaced by a fly-ash layer. Significant improvement is obtained when depth of fly-ash layer is 1.5 times width of footing.

2 Fly-ash, which is an industrial waste, can be effectively used on embankments and under road pavements as a filling material.

3 The use of geogrid as a reinforcement in the substituted fly-ash layer not only increases the capacity of load bearing, but also decreases the depth of the replaced fly-ash over a soft clay layer.

4 Geogrid impact as soil reinforcement depends on the position of the footing, geogrid is more productive in situations where the foundation is positioned close to the slope edge, and its effectiveness decreases when foundations are moved away from the edge of the slope.

5 With the growing number of geogrid-reinforcement sheets and the length of geogrid sheet, the ability to carry load increases. For a footing installed at the slope edge that rests on the thickness of $1.5 \mathrm{~B}$ of the substituted fly-ash sheet, appropriate anchoring length should be granted for each geogrid sheet or layer and overall number of geogrid layers. A geogrid length of five times the size of the footing $(\mathrm{L}=5 \mathrm{~B})$ and recommended number of geogrid layers were identified in the current research. The maximum shift happens when the number of reinforcing layers is 4-5.

6 With regards to the load carrying ability of reinforced and unreinforced slopes, the impact of the edge gap of the footing on the fly-ash layer over an earthen slope is important. With increasing in the space between the footing and slope edge, the load carrying potential normally increases. However, the overall load carrying potential of the footing does not appear to be influenced by the slope existence at an edge distance larger than 4B.

7 The optimum geogrid-reinforcement value from the current study depends on the configuration of the reinforcement. For optimal advantage, the suggested geogrid depth $(\mathrm{u} / \mathrm{B})$ and spacing $(\mathrm{x} / \mathrm{B})$ are 0.25 and 0.5 of the width of footing respectively. 


\section{References}

[1] M. A. El Sawwaf, "Behavior of strip footing on geogrid-reinforced sand over a soft clay slope," Geotext. Geomembranes, vol. 25, no. 1, pp. 50-60, 2007, doi: 10.1016/j.geotexmem.2006.06.001.

[2] A. K. Choudhary, J. N. Jha, and K. S. Gill, "Laboratory investigation of bearing capacity behaviour of strip footing on reinforced flyash slope," Geotext. Geomembranes, vol. 28, no. 4, pp. 393-402, 2010, doi: 10.1016/j.geotexmem.2009.09.007.

[3] C. Yoo, "Laboratory investigation of bearing capacity behavior of strip footing on geogrid-reinforced sand slope," Geotext. Geomembranes, vol. 19, no. 5, pp. 279-298, 2001, doi: 10.1016/S02661144(01)00009-7.

[4] Kulbir Singh Gill, Anil Kumar Choudhary, Jagada Nand Jha, and Sanjay Kumar Shukla, "LoadBearing Capacity of the Footing Resting on a Reinforced Fly Ash Slope,” J. Civ. Eng. Archit., vol. 6, no. 5, 2012, doi: 10.17265/1934-7359/2012.05.011.

[5] S. A. Naeini, B. Khadem Rabe, and E. Mahmoodi, "Bearing capacity and settlement of strip footing on geosynthetic reinforced clayey slopes," J. Cent. South Univ. Technol. (English Ed., vol. 19, no. 4, pp. 1116-1124, 2012, doi: 10.1007/s11771-012-1117-z.

[6] P. V.S. N. P. Kumar, "Bearing capacity of strip footing on clay soil reinforced with metal strips and with anchors," Lect. Notes Civ. Eng., vol. 14, no. December, pp. 77-84, 2019, doi: 10.1007/978-98113-0559-7_9.

[7] M. Raftari, K. A. Kassim, A. S. A. Rashid, and H. Moayedi, "Settlement of shallow foundations near reinforced slopes," Electron. J. Geotech. Eng., vol. 18 D, no. March 2014, pp. 797-808, 2013.

[8] . B. H., "Behavior of Square Footing Resting on Reinforced Sand Subjected To Incremental Loading and Unloading," Int. J. Res. Eng. Technol., vol. 03, no. 18, pp. 67-75, 2014, doi: 10.15623/ijret.2014.0318011.

[9] E. B. Altalhe, M. R. Taha, and F. M. Abdrabbo, "Behavior of strip footing on reinforced sand slope," J. Civ. Eng. Manag., vol. 21, no. 3, pp. 376-383, 2015, doi: 10.3846/13923730.2014.890646.

[10] H. Zeydi and A. H. Boushehrian, "Experimental and Numerical Study of Bearing Capacity of Circular Footings on Layered Soils With and Without Skirted Sand Piles," Iran. J. Sci. Technol. - Trans. Civ. Eng., vol. 44, no. 3, pp. 949-958, 2020, doi: 10.1007/s40996-019-00284-w.

[11] T. Yetimoglu, M. Inanir, and O. E. Inanir, "A study on bearing capacity of randomly distributed fiberreinforced sand fills overlying soft clay,” Geotext. Geomembranes, vol. 23, no. 2, pp. 174-183, 2005, doi: 10.1016/j.geotexmem.2004.09.004.

[12] V. sharma and A. kumar, "Strength and Bearing Capacity of Ring Footings Resting on FibreReinforced Sand," Int. J. Geosynth. Gr. Eng., vol. 3, no. 1, p. 0, 2017, doi: 10.1007/s40891-017-00866.

[13] S. Benmebarek, S. Djeridi, and N. Benmebarek, "Effect of geosynthetic reinforcement filled with aggregate on the bearing capacity of sand," Int. J. Geotech. Eng., vol. 14, no. 6, pp. 589-602, 2020, doi: 10.1080/19386362.2018.1541159.

[14] A. Mittal and S. Shukla, "Strength improvement of poor subgrade soil reinforced with polyester biaxial geogrid," Jordan J. Civ. Eng., vol. 13, no. 2, pp. 214-225, 2019.

[15] J. Li, C. Tang, D. Wang, X. Pei, and B. Shi, "Effect of discrete fibre reinforcement on soil tensile strength," J. Rock Mech. Geotech. Eng., vol. 6, no. 2, pp. 133-137, 2014, doi: 10.1016/j.jrmge.2014.01.003.

[16] J. C. Chang, J. J. Liao, and Y. W. Pan, "Bearing behavior and failure mechanism of a shallow foundation located on/behind the crest of a poorly cemented artificial sandstone," Int. J. Rock Mech. Min. Sci., vol. 45, no. 8, pp. 1508-1518, 2008, doi: 10.1016/j.ijrmms.2008.01.013.

[17] A. P. Report et al., "Behavior of Strip Footing on Multi Layered Geogrid Reinforced Sand Bed Behavior of Strip Footing on Multi Layered Geogrid Reinforced Sand Bed," 2007.

[18] M. A. El Sawwaf, "Strip footing behavior on pile and sheet pile-stabilized sand slope," AEJ Alexandria Eng. J., vol. 43, no. 1, pp. 41-54, 2004, doi: 10.1061/(asce)1090-0241(2005)131:6(705).

[19] H. A. Alawaji, "Settlement and bearing capacity of geogrid-reinforced sand over collapsible soil," Geotext. Geomembranes, vol. 19, no. 2, pp. 75-88, 2001, doi: 10.1016/S0266-1144(01)00002-4. 
[20] A. Marto, M. Oghabi, and A. Eisazadeh, "The Effect of Geogrid Reinforcement on Bearing Capacity Properties of Soil Under Static Load; A Review, ”Electron. J. Geotech. Eng., vol. 18 J, pp. 1881-1898, 2013.

[21] Y. Tavangar and I. Shooshpasha, "Experimental and Numerical Study of Bearing Capacity and Effect of Specimen Size on Uniform Sand with Medium Density, Reinforced with Nonwoven Geotextile, "Arab. J. Sci. Eng., vol. 41, no. 10, pp. 4127-4137, 2016, doi: 10.1007/s13369-016-2101-y.

[22] K. Halder and D. Chakraborty, "Probabilistic bearing capacity of strip footing on reinforced soil slope," Comput. Geotech., vol. 116, no. August, p. 103213, 2019, doi: 10.1016/j.compgeo.2019.103213.

[23] A. Ghosh, A. Ghosh, and A. K. Bera, "Bearing capacity of square footing on pond ash reinforced with jute-geotextile," Geotext. Geomembranes, vol. 23, no. 2, pp. 144-173, 2005, doi: 10.1016/j.geotexmem.2004.07.002.

[24] K. S. Gill, A. Kaur, and J. N. Jha, "Numerical study of footing on single layer reinforced slope," 2011.

[25] S. K. Das and Yudhbir, "Geotechnical Characterization of Some Indian Fly Ashes," J. Mater. Civ. Eng., vol. 17, no. 5, pp. 544-552, 2005, doi: 10.1061/(asce)0899-1561(2005)17:5(544). 